\title{
Research and Analysis on Personal Trainer Service Quality of Health Club in Xianning City
}

\author{
Yameng $\mathrm{Li}^{1,}$, , Shuangjun $\mathrm{Li}^{2, \mathrm{~b}}$ \\ ${ }^{1}$ Hubei University of Science and Technology, Xianning, Hubei, 437100 \\ ${ }^{2}$ Hubei University of Science and Technology, Xianning, Hubei, 437100
}

Keywords: Xianning City, Health Club, Personal Trainer, Service Quality

\begin{abstract}
Along with economic development, people's lifestyles are changing to happen, "spend money on health" concept has been accepted by all, people will choose to go to a health club, a more scientific and more professional sports. Choose a personal trainer will not only become a more scientific and professional fitness way, it has become one of the most fashionable consumption. Personal trainer service quality has started to become a resumed increase rates, to create profits, to promote enterprise development tool is the key to health club in a highly competitive environment to survive. This paper is mainly based on in SERVQUAL model, the quality of Xianning commercial health club personal trainer service evaluation analysis, according to personal trainer members' rating, understand the status of commercial health club personal trainer service quality, main problems service at Present and accordingly make recommendations, suggestions and opinions for sustainable development of health club personal trainer in Xianning.
\end{abstract}

\section{Introduction}

Quality of Service is the core personal trainer profession, personal trainer to do the work, it is necessary to provide quality services to members. Quality services can improve member satisfaction, and enhance member loyalty to a personal trainer, to stimulate the members to make an oral publicity for a personal trainer, personal trainer to establish the image. Currently for personal trainer services research in this area is less. I believe that the focus on quality of service personal trainer, personal training to understand the needs of members, analyze the impact personal trainer service quality factors and quality of service to member satisfaction and renewal rates for class fitness club long-term development is very important. This paper is mainly based on in SERVQUAL model, the quality of Xianning commercial health club personal trainer service evaluation analysis, according to personal trainer members' rating, understand the status of commercial health club personal trainer service quality, main problems service at Present and accordingly make recommendations, suggestions and opinions with a view to Xianning health club personal trainer sustainable development.

\section{Subjects and Methods}

Study Subjects. In this project is the quality of personal trainer services. Subject is Xianning seven health club personal trainer (50), PT members (100). Fitness club is owned separately Xianning Road fitness club, Austria Sofitel fitness club, fitness club winds, flashing fitness club, fitness club CosMedix Lake Branch fitness club, fitness club moving force.

Research Methods. In this paper, based on the content, objectives and tasks required to collect data pool in academic journals theory about personal trainer status and quality of service and other related aspects of information, access to a large number of domestic and foreign-related quality of service documents and books related data analysis finishing understand the status of research in this area at home and abroad.

According to the needs of the contents of this paper, to be in Xianning City, seven health club personal trainer, personal training members and ordinary members to investigate. This questionnaire based on quality of service SERVUAL evaluation model from tangibles, responsiveness, reliability, empathy four dimensions questionnaire design, and after about sports sociology expert examination, 
based on expert feedback, further modifications were made to form a formal questionnaire. Personal trainer questionnaires were distributed and 50 parts of PT members questionnaires were distributed and 200 copies. Wherein questionnaire issued on personal trainer are in full recovery, recycling 196 PT members.

Questionnaire recovered organize, application SPSS17.0 statistical software for which the data valid questionnaires were analyzed. And mainly do the mean probability analysis for the data.

\section{Results and Analysis}

The Metrics of Personal Trainer Service Quality. American Marketing experts Parsuraman, Zeithaml and Berry (referred PZB) presented the service quality gap analysis model in 1985, SERVQUAL evaluation model. They believe that the quality of service should include the following four aspects, namely, reliability, empathy, tangibles, responsiveness. Reliability refers to reliably and accurately ability to fulfill service commitments; refers to tangible equipment, facilities, personnel and other promotional materials; empathy is defined as the sake of customers and to pay special attention to the customer; the response is It refers to the focus on the customer service and rapidly increasing levels of desire.

\section{Reliability Analysis on Personal Trainer}

Table 1 The selecting attached conditions of personal trainer for training members $(\mathrm{N}=196)$

\begin{tabular}{lcc}
\hline Condition & Number $(\mathrm{n})$ & Proportion (\%) \\
\hline Gender & 108 & $55.1 \%$ \\
Age & 135 & $68.9 \%$ \\
Working Time & 66 & $84.7 \%$ \\
Experience Before Work & 31 & $15.9 \%$ \\
Educational Background & 17 & $8.9 \%$ \\
With Vocational Certificate & 113 & $57.7 \%$ \\
\hline
\end{tabular}

Reliability refers to reliably and accurately ability to fulfill service commitments. As a service industry, the level of quality of service perceived by the service personnel, the study from the perspective of private education Member choose what personal trainer attached conditions, that is, for members who choose to follow their hearts, personal trainer owns what conditions It is reliable and credible. As can be seen from Table 1, factors PT members choose a personal trainer the main consideration gender, age, employment time, whether a qualification these four points. 55.1\% of members will choose a personal trainer from a gender viewpoint, some female members will choose the muscles turn out to be a better man to do his own personal trainer coach, because I think more reliable; while some women members would choose female coach, because training up more convenient, and sometimes female coach for male members is also particularly sought-after. $68.4 \%$ of the members in the choice of a personal trainer will take into account the age of the other. With the development of the times, fitness increasingly popular with young people, the moment has become one of the healthy life style of the most fashionable. More common topic among the young and the young members of the coach, the coach is more mature people trust.

Empathy Analysis of Personal Trainer. That concern and empathy for the customer and provide personalized service. For example: when the member birthday or holiday gift to members, will remind class members the day before school hours and so on.

Table 2 The empathy questionnaire of personal trainer by private members $(\mathrm{N}=196)$

Content Always Often Occasionally None




\begin{tabular}{|c|c|c|c|c|c|c|c|c|}
\hline & $\mathrm{n}$ & $\%$ & $\mathrm{n}$ & $\%$ & $\mathrm{n}$ & $\%$ & $\bar{n}$ & $\%$ \\
\hline $\begin{array}{l}\text { Telephone or SMS tips } \\
\text { one day before class }\end{array}$ & 116 & $59.1 \%$ & 73 & $37.2 \%$ & 7 & $3.7 \%$ & 0 & $0 \%$ \\
\hline $\begin{array}{l}\text { Prepare sports towels, sports } \\
\text { goggles for members before class }\end{array}$ & 16 & $8.2 \%$ & 51 & $26 \%$ & 87 & $44.3 \%$ & 42 & $21.4 \%$ \\
\hline $\begin{array}{l}\text { Send birthday and holiday blessings } \\
\text { for member }\end{array}$ & 28 & $14.3 \%$ & 107 & $54.6 \%$ & 61 & $31.1 \%$ & 0 & $0 \%$ \\
\hline $\begin{array}{l}\text { Stretching relaxation for members } \\
\text { after class }\end{array}$ & 140 & $72.4 \%$ & 25 & $12.2 \%$ & 11 & $5.1 \%$ & 0 & $0 \%$ \\
\hline $\begin{array}{l}\text { Ask members physical condition } \\
\text { after class }\end{array}$ & 121 & $61.7 \%$ & 39 & $19.9 \%$ & 36 & $18.4 \%$ & 0 & $0 \%$ \\
\hline $\begin{array}{l}\text { Initiative to produce training } \\
\text { content before class }\end{array}$ & 24 & $12.2 \%$ & 59 & $30.1 \%$ & 82 & $41.8 \%$ & 31 & $15.8 \%$ \\
\hline
\end{tabular}

Personal trainer service quality depends mainly on the personal professionalism. For the purchase of the members of private lessons and personal trainer services are also differences. Although basically a personal trainer before the class will be able to remind the members of the class of the day, but only 5.1\% of personal trainers can do it every time waiting for the arrival of members in the foreground, in fact, this is just a small move, but as a personal trainer this role lot of extra points, the coach feels very professional. 59.2 percent of personal trainers are not used to take the initiative to show the day of the training program for members; each lesson can be done to monitor the heart rate of the PT members and coaches are rare. Members keep monitoring heart rate during exercise, not only allow personal trainer a clear understanding of the physical condition of membership at this time, but also allows members of a personal trainer is more trust. $72.4 \%$ of the personal trainer will be completed after training to members to relax and stretch. A good stretching method not only allows members to feel the professional quality of the coaches, and members can accelerate the elimination of fatigue after exercise, help the body recover faster, reduce body aches the next day. Members can at birthday or holiday blessings to members represented only $14.3 \%$ of the personal trainer, this behavior can make members more confidence in your own personal trainer, thereby increasing the rate of renewal courses.

The Tangible Analysis of Personal Trainer

Table 3 The tangible questionnaire of personal trainer $(\mathrm{N}=196)$

\begin{tabular}{|c|c|c|c|c|c|c|c|c|}
\hline \multirow[t]{2}{*}{ Content } & \multicolumn{2}{|c|}{ Always } & \multicolumn{2}{|c|}{ Often } & \multicolumn{2}{|c|}{ Occasionally } & \multicolumn{2}{|c|}{ None } \\
\hline & $\mathrm{n}$ & $\%$ & $\mathrm{n}$ & $\%$ & $\mathrm{n}$ & $\%$ & $\mathrm{n}$ & $\%$ \\
\hline $\begin{array}{l}\text { Personal trainer is in good spirits } \\
\text { in class }\end{array}$ & 123 & $62.8 \%$ & 34 & $17.3 \%$ & 39 & $19.9 \%$ & 0 & $0 \%$ \\
\hline $\begin{array}{l}\text { Personal trainer's clothes is clean and } \\
\text { with fresh breath }\end{array}$ & 147 & $75 \%$ & 36 & $18.4 \%$ & 13 & $6.6 \%$ & 0 & $0 \%$ \\
\hline $\begin{array}{l}\text { Show you the contents of the class } \\
\text { before each class }\end{array}$ & 79 & $40.3 \%$ & 87 & $44.4 \%$ & 22 & $11.2 \%$ & & $1 \%$ \\
\hline
\end{tabular}

It involves tangible physical facilities, appearance and other equipment and service personnel. As can be seen from Table 11, a personal trainer in personal image more attention, give more positive attitude toward membership. However, only 39.8\% of the personal trainer will show content before 
class to class members, which shows that in Xianning City personal trainer has done is not enough. Show courses are also part of a personal trainer, but also a manifestation of a personal trainer is responsible for the recognition.

Response Analysis of Personal Trainer

Table 4 Questionnaire on personal trainer provide service and solve problem for members $(\mathrm{N}=196)$

\begin{tabular}{ccccc}
\hline Content & Always & Often & Occasionally & None \\
\hline Number $(\mathrm{n})$ & 130 & 37 & 29 & 0 \\
Proportion $(\%)$ & $66.3 \%$ & $18.9 \%$ & $14.8 \%$ & $0 \%$ \\
\hline
\end{tabular}

Responsive means to help customers quickly and provide the level of service desire. As can be seen from Table 4, a personal trainer to teach members of the private sense of service needs to be improved. Personal trainer in front of members of the actor in different roles: instructor, supervisor, friend, service personnel, etc. sparring. But the most important role is to service personnel. Personal trainer service provided is intangible and the ultimate aim is to meet the fitness needs of members. Provide timely service members when needed, when members encounter difficulties in need of help, in a timely manner to support it. People interact with each other, if the personal trainers in the most sincere attitude towards members of their own private education, private education members will maximize the trust of a personal trainer.

\section{Conclusions}

The contents of personal trainer's class is single and the majority remain in the exercise equipment; a qualified personal trainer situation is more optimistic; Personal Trainer empathy, additional services, needs to be strengthened. As preparing sports goggles, sports towels for members. Although these are small details, but we can do for the personal trainer of professional degrees plus points; a personal trainer in personal image to do better, to be maintained; club for a personal trainer service quality management is not perfect, there is room for improvement.

The personal trainer should create their own special teaching and training methods; when their own publicity, should have a good degree; improve Member intuitive judgment and sensitivity; fitness club managers should pay attention to the quality of services personal trainer, fitness trainer and services related to the establishment of quality management system, establish a specific and good internal training system. Members should exercise properly their rights, commitment perceived personal trainer is not completed, and even fraud, they should promptly communicate with the club manager, to protect their legitimate interests.

Found:The teaching research topic of 2015（2015-xc-016）;The scientific research project of 2014 （ky14033）

\section{References}

[1] Ping Chen, Juan Xu: Beijing Sport University, Vol. 2 (2009) No 53, p.25-26

[2] State Sports Administrative Guidance Center Fitness Personal Trainer Training Management Requirements. Social Word, (2004) No 45 